\title{
Evaluation of Forecasting Models for Fusarium Head Blight of Wheat Under Growing Conditions of Quebec, Canada
}

\author{
M.-E. Giroux, Département de phytologie, Université Laval, Québec, QC, G1V 0A6, Canada; G. Bourgeois, Agriculture and Agri-Food \\ Canada, Saint-Jean-sur-Richelieu, QC, J3B 3E6, Canada; Y. Dion, Centre de recherche sur les grains (CÉROM), Saint-Mathieu-de-Beloeil, \\ QC, J3G 0E2, Canada; S. Rioux, CÉROM, Québec, QC, G1P 3W8, Canada; D. Pageau, Agriculture and Agri-Food Canada, Normandin, \\ QC, G8M 4K3, Canada; S. Zoghlami, Fédération des producteurs de cultures commerciales du Québec, Longueuil, QC, J4H 4G4, Canada; \\ C. Parent, Ministère de l'Agriculture des Pêcheries et de l'Alimentation du Québec, Québec, QC, G1R 4X6, Canada; E. Vachon, Moulins \\ de Soulanges, Saint-Polycarpe, QC, J0P 1X0, Canada; and A. Vanasse, Département de phytologie, Université Laval, Québec
}

\begin{abstract}
Giroux, M.-E., Bourgeois, G., Dion, Y., Rioux, S., Pageau, D., Zoghlami, S., Parent, C., Vachon E., and Vanasse, A. 2016. Evaluation of forecasting models for Fusarium head blight of wheat under growing conditions of Quebec, Canada. Plant Dis. 100:1192-1201.

Fusarium head blight (FHB) is a fungal disease of wheat (Triticum aestivum L.) causing frequent economic losses to farmers under growing conditions of Eastern Canada. To assess risks associated with this disease and guide fungicide use decisions, many researchers from numerous countries have developed weather-based forecasting models. This work aims at evaluating which model produces the most accurate predictions of disease infection or deoxynivalenol (DON) content under climatic conditions occurring in Quebec. Spring wheat was grown during two seasons and winter wheat during one season at four experimental sites located in Quebec. Nine selected models for evaluation produced predictions of DON content (Canada and Italy), disease incidence (Argentina

and Italy), and probability of epidemics (United States). Data from plots without fungicide (52 samples) were used to test the models listed above. Reliability of the selected forecasting models was evaluated with receiver operating characteristic (ROC) curve analysis. DON content $(\geq 1 \mathrm{ppm})$ was the best crop damage indicator to differentiate epidemic (cases) and nonepidemic (controls) situations. Two American and the Argentinean forecasting models were more reliable than the others when the thresholds recommended in the literature were adjusted using the results for the ROC curve analyses. Those models are a good starting point for the implementation of an FHB forecasting system adapted to wheat production in Quebec.
\end{abstract}

Fusarium head blight (FHB) is a fungal disease that severely affects wheat (Triticum aestivum L.) in Eastern Canada when warm and humid weather conditions occur during flowering (Bailey et al. 2004; McMullen et al. 1997). Fusarium graminearum Schwabe (teleomorph: Gibberella zeae (Schwein.) Petch) is the most common pathogen causing this disease (Parry et al. 1995). This species produces deoxynivalenol (DON), which is a mycotoxin that makes wheat unsuitable for food and feed (Desjardins 2006). Several methods are already known to reduce the risk and impact of this disease: selection of wheat cultivars with partial or quantitative resistance to FHB, rotation with nonhost plants to break the disease cycle, and fungicide application. In Canada, the Canadian Food Inspection Agency regulates DON content in wheat for human consumption. Grain lots containing higher numbers of damaged kernels are classified in a lower-quality grade at the elevator. However, on the grain market of Eastern Canada, grain with higher DON content is also classified in a lower-quality grade and pricing (Canadian Grain Commission 2015). For food, millers accept lots with DON at a maximum of 2 ppm (Canadian Food Inspection Agency 2012). To minimize the adverse effects of DON on animal health, Canadian authorities recommend different maximum thresholds for feed (Canadian Grain Commission 2015). For example, DON at a maximum of $1 \mathrm{ppm}$ is recommended in diets for swine, young calves, and lactating dairy animals, while a maximum of $5 \mathrm{ppm}$ is accepted in diets for cattle and poultry. In short, impacts of mycotoxins (e.g., DON) on the economy and on human or animal health are not to be neglected.

Corresponding author: G. Bourgeois; E-mail: Gaetan.Bourgeois@AGR.GC.CA

Accepted for publication 30 December 2015.

http://dx.doi.org/10.1094/PDIS-04-15-0404-RE

This article is in the public domain and not copyrightable. It may be freely reprinted with customary crediting of the source. The American Phytopathological Society, 2016.
To assess risks associated with this disease and guide fungicide application decisions, weather-based models forecasting FHB infection or DON content in wheat grain have been developed in many countries. Despite the known consequences of FHB, factors increasing disease risks are not always objectively assessed and provided in a timely manner and in a form that can readily be used by the farmer to make prompt fungicide use decisions. To better understand the factors that influence the relationships among pathogen, host, and environment, a comprehensive model would preselect for the user the most favorable conditions and assess the risk of disease (McCown 2002). According to predicted disease pressure, wheat producers are able to optimize fungicide applications and target specific markets before wheat harvest (Landschoot et al. 2013).

Forecasting models can be either empirical or mechanistic. The first is simpler and easier to use and can be designed in a relatively short period of time (Prandini et al. 2009). Empirical models expose the relationships between weather conditions and FHB using statistical models, and they are usually reliable in the regions where they were developed. However, they may need some adjustments to be as effective in other locations (Prandini et al. 2009). Mechanistic models include a lot of information and are more difficult to develop. Many forecasting models for FHB of wheat have been developed around the world, in Canada (Hooker et al. 2002; Schaafsma and Hooker 2007), the United States (De Wolf and Isard 2007; De Wolf et al. 2003; McMullen et al. 2012; Molineros 2007; Shah et al. 2013 , 2014), Argentina (Moschini and Fortugno 1996; Moschini et al. 2001, 2004), Brazil (Del Ponte et al. 2005), Belgium (Landschoot et al. 2013), The Netherlands (Van Der Fels-Klerx et al. 2010), Switzerland (Musa et al. 2007), and Italy (Rossi et al. 2003). Currently, there is no forecasting model that has been developed or evaluated for FHB of wheat for the province of Quebec in Canada. Because of their specificity to their region of origin, few FHB models have been adapted to other regions. Nevertheless, the Italian, Argentinean, and Canadian models have been adjusted for other crop conditions and used in countries outside their region of origin (Del Ponte et al. 2005; Moschini et al. 2004; Schaafsma and Hooker 2007; 
Váňová et al. 2009). In addition, few studies have compared the performance of several plant disease forecasting models to assess which fit best in a specific region. Thus, the current study was conducted to determine which model produces the most accurate predictions of FHB infection or DON content, and to establish optimal decision model threshold and crop damage indicators under weather conditions occurring in Quebec.

\section{Materials and Methods}

Data collection and FHB predictions. Phenological, epidemiological, and weather data were collected for the evaluation of forecasting models for FHB of wheat. The field experiments were conducted during the growing seasons of 2011 and 2012 at four experimental sites that are representative of different cereal production areas of the province of Quebec in Canada (Table 1). The sites were located at Agriculture and Agri-Food Canada in L'Acadie and Normandin, at the Centre de recherche sur les grains (CÉROM) in Saint-Mathieu-de-Beloeil, and at the Agronomy Research Station of Laval University in Saint-Augustin-de-Desmaures. At each site, red spring wheat trials were implemented for the 2011 and 2012 growing seasons and a hard red winter wheat trial was set up in the fall of 2011. For each spring wheat trial site, a split-plot design with four replicates was set up. The main plot was seeding date (early, intermediate, and late) (Table 2). Factorial arrangements of cultivar and fungicide treatment (i.e., with and without fungicide application) were used as the subplots. Cultivars used were 'AC Barrie' (susceptibility level 2) and 'Torka' (susceptibility level 4). Susceptibility levels are expressed on a scale from 1 to $9(1=$ low susceptibility and $9=$ high susceptibility) (Réseaux Grandes Cultures du Québec 2011). There were 12 treatment combinations per trial and 48 plots per site each year (three seeding dates $\times$ two cultivars $\times$ two fungicide treatments [with or without] $\times$ four blocks). For the winter wheat trial at each of the four sites, only one seeding date, one cultivar ('Warthog', susceptibility level 4), and two fungicide treatments were tested. A randomized complete block design (four blocks) was used to study the impact of fungicide application (i.e., fungicide applied versus not applied). For all wheat trials, the seeding rate was 425 seeds $\mathrm{m}^{-2}$ and plot sizes are indicated in Table 1 for each experimental site. The fungicide used at flowering was PROSARO $250 \mathrm{EC}$, which is a mixture of tebuconazole $\left(125 \mathrm{~g} \mathrm{liter}^{-1}\right)$ and prothiconazole $(125 \mathrm{~g}$ liter ${ }^{-1}$ ), manufactured by Bayer Crop Science Inc. The application rate was active ingredient (tebuconazole and prothioconazole together) at $200 \mathrm{~g} \mathrm{ha}^{-1}$ in a total spray volume of 200 liters $\mathrm{ha}^{-1}$.

All factors (seeding date, cultivar, and fungicide treatment) and locations were selected to maximize the variability in infection risks and FHB impact under diverse environmental and weather conditions. This variability is essential to test forecasting models under a range of conditions, and to evaluate their effectiveness in epidemic and nonepidemic scenarios. Dates of early heading (Z51), heading (Z58), and flowering (Z65) were noted (Zadoks et al. 1974). Different seeding and flowering dates for AC Barrie, Torka, and Warthog wheat at each experimental site for 2011 and 2012 are shown in Table 2. In addition, several disease assessments for FHB were evaluated in each trial. Spikes at the milky stage (Z75) of development were collected to estimate the mean percentage of infected spikes and spikelets per plot, which was then used to calculate FHB index values for each plot (FHB index $=$ total number of infected spikelets/total number of spikelets $\times 100)$. After harvest, to evaluate Fusarium-damaged kernels (FDK), subsamples of $15 \mathrm{~g}$ were separated using a divider. Symptoms of FHB were visually assessed on 300 grains taken randomly from the subsample and FDK was calculated ([total FDK/total grains] $\times 100$ ). Grain samples of $300 \mathrm{~g}$ were then ground using the Cyclone sample mill 3010-30, 4477U (UDY Corporation, Fort Collins, CO). DON content was measured on these ground kernels using enzyme-linked immunosorbent assay kits (Veratox $5 / 5$ for Quantitative DON for DON $>0.5 \mathrm{ppm}$ and Veratox HS Quantitative High Sensitivity Test for DON $<0.5$ ppm; Neogen Corporation, Lansing, MI). Finally, temperature, precipitation, and relative humidity were recorded on an hourly basis using electronic sensors connected to an automatic weather station already operational at each experimental site.

Forecasting models of FHB are numerous and could not all be evaluated under climatic conditions of Quebec. The selected models differ in their climate or region of origin (Europe, North America, and South America) and in the parameters and periods used to predict FHB. Thus, nine forecasting models were evaluated in Quebec, which has a continental climate (Peel et al. 2007). The first model

Table 2. Seeding and flowering dates at all sites for spring and winter wheat in 2011 and $2012^{\mathrm{y}}$

\begin{tabular}{|c|c|c|c|c|}
\hline Dates $^{\mathbf{z}}$ & BE & LA & SA & NO \\
\hline \multicolumn{5}{|l|}{2011 Spring wheat } \\
\hline \multicolumn{5}{|l|}{ Seeding dates } \\
\hline D1 & May 13 & May 13 & May 12 & May 24 \\
\hline D2 & May 20 & May 26 & May 19 & June 3 \\
\hline D3 & May 25 & June 2 & May 25 & June 8 \\
\hline \multicolumn{5}{|l|}{ Flowering dates } \\
\hline \multicolumn{5}{|l|}{ AC Barrie } \\
\hline D1 & July 6 & July 7 & July 8 & July 13 \\
\hline $\mathrm{D} 2$ & July 10 & July 18 & July 11 & July 20 \\
\hline D3 & July 13 & July 22 & July 15 & July 23 \\
\hline \multicolumn{5}{|l|}{ Torka } \\
\hline D1 & July 10 & July 11 & July 11 & July 17 \\
\hline $\mathrm{D} 2$ & July 15 & July 22 & July 13 & July 24 \\
\hline D3 & July 19 & July 25 & July 19 & July 28 \\
\hline \multicolumn{5}{|l|}{2012 Spring wheat } \\
\hline \multicolumn{5}{|l|}{ Seeding dates } \\
\hline D1 & May 3 & May 7 & May 2 & May 4 \\
\hline $\mathrm{D} 2$ & May 12 & May 24 & May 7 & May 15 \\
\hline D3 & May 18 & May 30 & May 14 & May 22 \\
\hline \multicolumn{5}{|c|}{ Flowering dates } \\
\hline \multicolumn{5}{|l|}{ AC Barrie } \\
\hline D1 & June 28 & July 5 & June 27 & July 11 \\
\hline D2 & July 3 & July 8 & July 1 & July 13 \\
\hline D3 & July 7 & July 12 & July 5 & July 16 \\
\hline \multicolumn{5}{|l|}{ Torka } \\
\hline D1 & July 3 & July 5 & July 3 & July 9 \\
\hline D2 & July 8 & July 12 & July 6 & July 16 \\
\hline D3 & July 12 & July 16 & July 9 & July 20 \\
\hline \multicolumn{5}{|l|}{2012 winter Wheat } \\
\hline Seeding dates & September 23 & September 27 & August 27 & September 2 \\
\hline Flowering dates & June 1 & June 1 & June 11 & June 24 \\
\hline
\end{tabular}

${ }^{y}$ BE $=$ Saint-Mathieu-de-Beloeil, LA = L'Acadie, $S A=$ Saint-Augustin-deDesmaures, and $\mathrm{NO}=$ Normandin.

z Seeding dates: D1 = early, D2 = intermediate, and D3 = late. Dates of flowering: $50 \%$ of anthers are extruded (Z65) of plots without fungicide for the three seeding dates of the two different cultivars in all experimental sites.

Table 1. Experimental sites, locations, degree-days, soil types, plot dimensions, and cereal production zones in Quebec, 2011 to 2012

\begin{tabular}{|c|c|c|c|c|c|}
\hline Sites & Location & DD $^{\mathbf{y}}$ & Soil type & Plot dimensions $^{\mathbf{z}}$ & Zone \\
\hline Saint-Mathieu-de-Beloeil & Lat. $45^{\circ} 34^{\prime} \mathrm{N}$, Long. $73^{\circ} 12^{\prime} \mathrm{W}$ & 2,873 & Clay loams of St-Urbain series & $1.8 \mathrm{~m} \times 6.0 \mathrm{~m}$, R.s. $=0.18 \mathrm{~m}$ & 1 \\
\hline L'Acadie & Lat. $45^{\circ} 17^{\prime} \mathrm{N}$, Long. $73^{\circ} 20^{\prime} \mathrm{W}$ & 2,853 & Clay loam of Chambly series & $1.5 \mathrm{~m} \times 6.0 \mathrm{~m}$, R.s. $=0.15 \mathrm{~m}$ & 1 \\
\hline Saint-Augustin-de-Desmaures & Lat. $46^{\circ} 44^{\prime} \mathrm{N}$, Long. $71^{\circ} 30^{\prime} \mathrm{W}$ & 2,555 & Loams of Tilly series & $1.62 \mathrm{~m} \times 6.0 \mathrm{~m}$, R.s. $=0.18 \mathrm{~m}$ & 2 \\
\hline Normandin & Lat. $48^{\circ} 50^{\prime} \mathrm{N}$, Long. $72^{\circ} 33^{\prime} \mathrm{W}$ & 2,260 & Clay loam of Normandin series & $1.44 \mathrm{~m} \times 6.0 \mathrm{~m}$, R.s. $=0.18 \mathrm{~m}$ & 3 \\
\hline
\end{tabular}

${ }^{\mathrm{y}}$ Average of degree-days (DD, base temperature $>0{ }^{\circ} \mathrm{C}$ ) recorded at each experimental site in 2011 and 2012 between 1 April and 30 September.

${ }^{\mathrm{z}}$ R.s. = row spacing. 
was reported by Hooker et al. (2002) and was developed in Ontario (Canada). It is an empirical model, predicting DON content (in ppm) at harvest with different equations related to three time periods around heading (Z58). Weather variables used in this model are the number of days with precipitation $>5 \mathrm{~mm}$, the number of days with daily minimum temperature $<10^{\circ} \mathrm{C}$, and the number of days with daily maximum temperature $>32^{\circ} \mathrm{C}$. The second model was a commercially available forecasting system known as DONcast, which is another Canadian model operated by Weather INnovations Consulting LP (WIN, Chatham, Ontario, Canada), based on the forecasting model of Hooker et al. (2002). This system also predicts DON (in ppm) in grain at harvest using weather conditions in five distinct time periods around heading (Z58) (Schaafsma and Hooker 2007). Total precipitation (in millimeters); daily average, minimum, and maximum temperatures $\left({ }^{\circ} \mathrm{C}\right)$; and relative humidity (percent) are used alone or in combination to make predictions (Schaafsma and Hooker 2007). Cultivar, crop rotation, and tillage also influence assessments generated by DONcast. This forecasting system can predict DON levels above or below the threshold of $1 \mathrm{ppm} 80$ to $85 \%$ of the time, according to Schaafsma and Hooker (2007).

In the United States, several empirical models forecasting probabilities of FHB outbreaks have been developed over the last decade under continental and semiarid climates (De Wolf et al. 2003; Haran et al. 2010; Molineros 2007; Peel et al. 2007; Shah et al. 2013, 2014). To predict the probability of epidemics, the three selected models (A, B, and I), as suggested by De Wolf et al. (2003) in their discussion, were developed using the number of hours with precipitation 7 days before flowering (Z65) (DPPT7: model I), the number of hours with a temperature between 15 and $30^{\circ} \mathrm{C} 7$ days before flowering (T15307: models B and I), and the number of hours with both a relative humidity $\geq 90 \%$ and a temperature between 15 and $30^{\circ} \mathrm{C}$ ending 10 days after flowering (TRH9010: models A and B). The De Wolf I model is then based on weather observations only prior to flowering (7 days), the De Wolf A model on weather observations only after flowering (10 days), and the De Wolf B model on weather observations both prior to and after flowering (17 days). Probabilities of FHB epidemics are defined by the chances that field severity reaches $10 \%$ or more. The severity corresponds to the percentage of infected spikelets and the probability varies between 0 and 1 . An outbreak is forecasted when the critical predicted probability is reached or exceeded, which is usually not more than 0.5 . Furthermore, Molineros (2007) developed empirical models based on the work by De Wolf et al. (2003). The selected model of Molineros (2007) only uses the average relative humidity (percent) for the 7 days before flowering (Z65) and integrates four levels of cultivar susceptibility to FHB to predict the probability of an epidemic, which also varies between 0 and 1 . For the evaluation of this model, only the most susceptible level was considered. Similar to De Wolf et al. (2003), Molineros (2007) defines an epidemic as a field where the severity exceeds $10 \%$. The critical predicted probability, or decision threshold, for this forecasting model is 0.5 . The De Wolf et al. (2003) models (A, B, and I) and Molineros (2007) model are not being used anymore for actual FHB risk forecasting in the United States because they were replaced by other models that were developed recently (Shah et al. 2013, 2014).

In Argentina, Moschini et al. (2001) developed an empirical model predicting the incidence of FHB, which is the percentage of infected heads, using cultivar susceptibility and 2-day periods where rainfall exceeds $0.2 \mathrm{~mm}$ and relative humidity is above $78 \%$. They also use maximum and minimum temperatures to calculate degree-days between 9 and $30^{\circ} \mathrm{C}$. The observed period starts at the beginning of heading (Z51) and extends to the accumulation of 550 degreedays. There is no action threshold; the model predicts directly the impacts of the disease for warm, temperate climates of the country (Peel et al. 2007). The final forecasting system was developed in Italy by Rossi et al. (2003), and this model uses the average temperature, number of hours where relative humidity is above $80 \%$, total precipitation (in millimeters), and the intensity of rainfall from heading (Z58) until harvest to predict risk of infection and accumulation of mycotoxins in kernels with two different models. The index of infection risk varies between 5 and 35 and the index of accumulation of toxins is generally between 0 and 2 . These indices are accumulated daily. Those mechanistic models consist of three main equations that are all related to the epidemiological cycle of FHB in wheat under temperate climates of the country (Peel et al. 2007).

Evaluations of the FHB risk models being tested were done in several steps. First, for all trials, average dates of important phenological stages (Z51, Z58, and Z65) observed within plots and relevant environmental parameters were used according to the needs of each model. The averages were calculated for each combination of seeding date and cultivar. In total, 52 combinations were tested ( 48 for spring wheat: 2 years $\times$ four sites $\times$ three seeding dates $\times$ two cultivars; and 4 for winter wheat: 1 year $\times$ four sites $\times$ one seeding date $\times$ one cultivar; Table 2 ). In addition, the dates of Z51, Z58, and Z65 for the 52 combinations were predicted with a phenological model of wheat using the software program CIPRA 18.11 (Agriculture and Agri-Food Canada, Saint-Jean-sur-Richelieu, Canada) (Plouffe et al. 2014). This second data set allowed for the analysis of the efficacy of the models using predicted phenological stages. The selected FHB forecasting models, except DONcast, were then integrated into the CIPRA program for further use. The predictions of the DONcast model were made by Weather INnovations Consulting LP using only data from observed crop phenologies for each year, site, seeding date, and cultivar combination.

Statistical analyses. To verify the performance of the selected forecasting models, predictions of FHB were compared with disease observations in the plots without fungicide using receiver operating characteristic (ROC) curve analysis (Madden 2006; Metz 1978). ROC curve analysis has long been used in several biomedical fields to assess the ability of diagnostic tests to differentiate healthy and sick patients (Metz 1978). Likewise, it is now used in plant pathology to assess the accuracy of forecasting models in classifying correctly cases and controls (Bondalapati et al. 2012; Carisse et al. 2008; Dewdney et al. 2007; Duttweiler et al. 2008; Elegbede et al. 2010; Hughes et al. 1999; Madden 2006; Madden et al. 2007; Turechek and Wilcox 2005; Wu et al. 2002).

At each site, assessments of FHB, also called crop damage indicators, included FHB index, percentage of FDK, and DON content in harvested grain. Mean FHB index, FDK, and DON content were calculated for the 52 combinations of seeding date, cultivar, and year (Table 2). These crop damage indicators were used to split the observations, or samples, into two subgroups. The first subgroup comprises "cases", which are epidemic situations where the observations were above the crop damage threshold, and the second includes "controls", which are nonepidemic situations where the observations were below the crop damage threshold. This classification is independent of the predictions of the selected models (Hughes et al. 1999). For FHB index, the crop damage thresholds selected were $10 \%$, as used by De Wolf et al. (2003) for the development of their models, and 5\% for comparison. For FDK, the crop damage thresholds used were 1.5\%, which is the limit for wheat intended for food in Canada (Canadian Grain Commission 2015), and $1 \%$ also for comparison. Finally, for DON content, the crop damage thresholds were $2 \mathrm{ppm}$, which is the limit allowed in wheat for human consumption (Canadian Food Inspection Agency 2012), and 1 ppm to compare the efficacy of another threshold. Lower thresholds for each crop damage indicator (namely, FHB index $\geq 10 \%$, FDK $\geq 1 \%$, and DON $\geq 1 \mathrm{ppm}$ ) were selected to account for uncertainties associated with field observations, weather measurements, model predictions, and so on. All crop damage indicators were used to measure the ability of each forecasting model to accurately predict the risk of FHB and to properly classify cases and controls in the data set. Models predicting infection risks were compared with all damage indicators, because FHB index, FDK, and DON content all result mostly from infections at flowering time. Models predicting DON accumulation were only compared with DON crop damage indicators, because DON content is also influenced by postinfection weather factors.

The overall performance of a forecasting model with each crop damage indicator can be condensed in an ROC curve (Metz 1978), a graphical plot that shows the relationship between the proportion of true positives (TPP, or sensitivity) and the proportion of false positives (FPP, or 1 - specificity) for all possible decision thresholds of the model (Hughes et al. 1999; Metz 1978). Model sensitivity is 
calculated by dividing the number of true positives, which are cases correctly predicted, by the total number of cases. Model specificity (true negative proportion [TNP]) is calculated by dividing the number of true negatives, which are controls correctly predicted, by the total number of controls. Furthermore, FPP is calculated by $1-$ TNP and the false negative proportion (FNP) is calculated by $1-$ TPP (Hughes et al. 1999; Madden et al. 2007; Yuen and Hughes 2002). ROC curves of each model are represented in a graph of TPP as a function of FPP. The ROC curve starts at $(0,0)$ and ends at the point $(1,1)$. The first point is related to the highest model decision threshold tested, corresponding to the lowest sensitivity and the highest specificity. For the point $(1,1)$, the lowest model decision threshold tested shows the highest sensitivity but the lowest specificity. In addition, the noinformation line is a straight line of reference between these two points with a slope equal to 1 (Hanley and McNeil 1982). An ROC curve approaching this line corresponds to a forecasting model not effective in differentiating cases and controls. In contrast, a model with high discriminatory power will curve away from the noinformation line with a TPP equal to 1 and an FPP approaching 0 (Hughes et al. 1999; Madden 2006).

To compare and evaluate the performance of the selected forecasting models, the area under the ROC curve (AUC) and its standard error were used (Hanley and McNeil 1982). As a reference, the AUC of the no-information line is 0.5 , while the AUC of a perfect model is 1 . The AUC, when calculated using the trapezoidal method, are the Mann-Whitney U-statistic from which a standard error can be determined (Hanley and McNeil 1982). Thus, a Z-statistic can be found and hypothesis testing can take place. The hypothesis tested to check the discriminatory ability of the model is that the AUC is not different from 0.5. In doing this test, the performance of the model is compared with random predictions. Because the ROC curves for the selected models were created from the same data sets, they cannot be considered independent and the correlation must be taken into consideration (Hanley and McNeil 1983). To compare the AUC of the nine selected models with their correlation, the method reported by DeLong et al. (1988), in which a nonparametric approach derived from the theory of U-statistics to produce an estimated covariance matrix, was used. ROC curve analyses and associated statistics were produced with the software program ROCTools (v.1.0.2; Institut Philippe-Pinel de Montréal, Montréal) (Allaire and Cismaru 2007).

Selection of best decision threshold. In ROC curve analyses, models are tested with a series of possible model decision thresholds, which are also called cut-off points. The best model decision threshold is the one where errors are minimized and where TPP and TNP are maximized (i.e., where there is the largest proportion of correct predictions of cases and controls). In this situation, the optimal model decision threshold can be found from Youden's index ( $\mathrm{J}=$ sensitivity + specificity - 1) (Biggerstaff 2000). Graphically, this model decision threshold will be the closest to the coordinate $(0,1)$. One can also compare model decision thresholds with likelihood ratios (LR). The LR of a positive prediction $(\mathrm{LR}+)$ is calculated with sensitivity/(1 specificity) or with TPP/FPP. The LR of a negative prediction (LR-) is (1 - sensitivity)/specificity or FNP/TNP (Biggerstaff 2000; Madden 2006). An effective model will have an LR+ above 1 and an LR- close to 0 (Madden 2006). The higher the LR+, the better the forecasting model at predicting the presence of disease. Conversely, the lower the LR-, the better the model at confirming the absence of disease (Biggerstaff 2000). In this study, LR+ and LR- were used to compare the best model decision threshold with recommended thresholds in the literature for the selected forecasting models.

\section{Results}

Frequency distributions and damage thresholds. In 2011, conditions were favorable for FHB at the experimental sites of Saint-Augustin-de-Desmaures and Normandin. However, at SaintMathieu-de-Beloeil and L'Acadie in 2011 and at all sites in 2012, dry conditions did not favor the development of the disease. Distribution of the 52 samples for DON content, FDK, and FHB index is shown in Figure 1. More than $60 \%$ of the samples contained DON at less than $0.5 \mathrm{ppm}$ while the other classes generally had a frequency of less than 10\%. For FDK assessments, samples in the extreme classes accounted for a greater proportion in the data set. In fact, nearly $50 \%$ of the samples had less than $1.5 \%$ FDK, and about $20 \%$ of the samples had FDK values of more than $9 \%$. Other classes contained less than $10 \%$ of the samples of the data set. FHB index seemed to be more evenly distributed among the different classes. Most of data set had less than 3\% infected spikelets.

Six different crop damage indicators were selected to produce six different ROC curve analyses. They were selected with independent criteria from the frequency distributions (Fig. 1) and they are justified based on Canadian regulations and by the literature (Canadian Food Inspection Agency 2012; De Wolf et al. 2003), as indicated previously. Depending on the crop damage indicator, the percentage of cases ranged from 1.9 to $61.5 \%$. The percentage of controls varied between 38.5 and $98.1 \%$ (Table 3). For ROC curve analyses, the optimal ratio of cases and controls varies depending on the model accuracy needed. However, the data set used must generally contain a proportion of at least $25 \%$ of cases or controls to produce valid analyses (Janes and Pepe 2006). For this reason, damage indicators of FHB index $\geq 5 \%$, FHB index $\geq 10 \%$, and DON $\geq 2$ ppm were rejected. The proportions of cases and controls in data sets of FDK $\geq 1 \%$, FDK $\geq 1.5 \%$, and DON $\geq 1 \mathrm{ppm}$ were sufficient to evaluate the performance of forecasting models in epidemic and nonepidemic situations.

ROC curve analyses. ROC curve analyses were performed under two different approaches. First, an analysis compared the observations of FHB to model predictions obtained using the observed phenological stages of wheat and then using the predicted phenological stages. The ROC curves are presented by damage indicator (FDK $\geq 1 \%$, FDK $\geq$ $1.5 \%$, and DON $\geq 1 \mathrm{ppm}$ ) for observed and predicted phenological stages (Fig. 2).

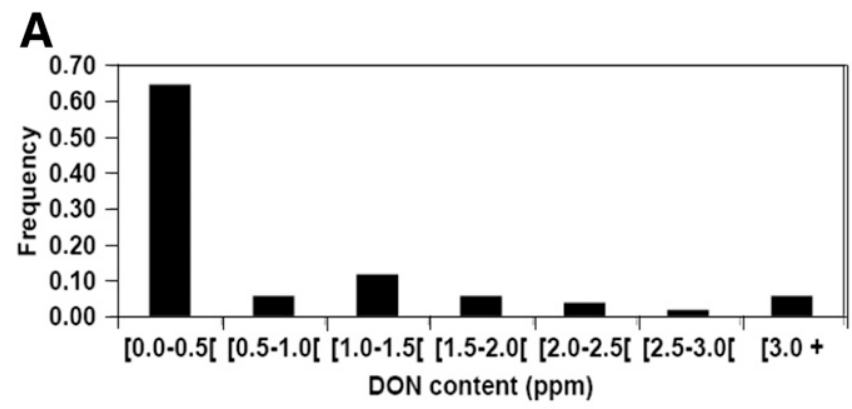

B
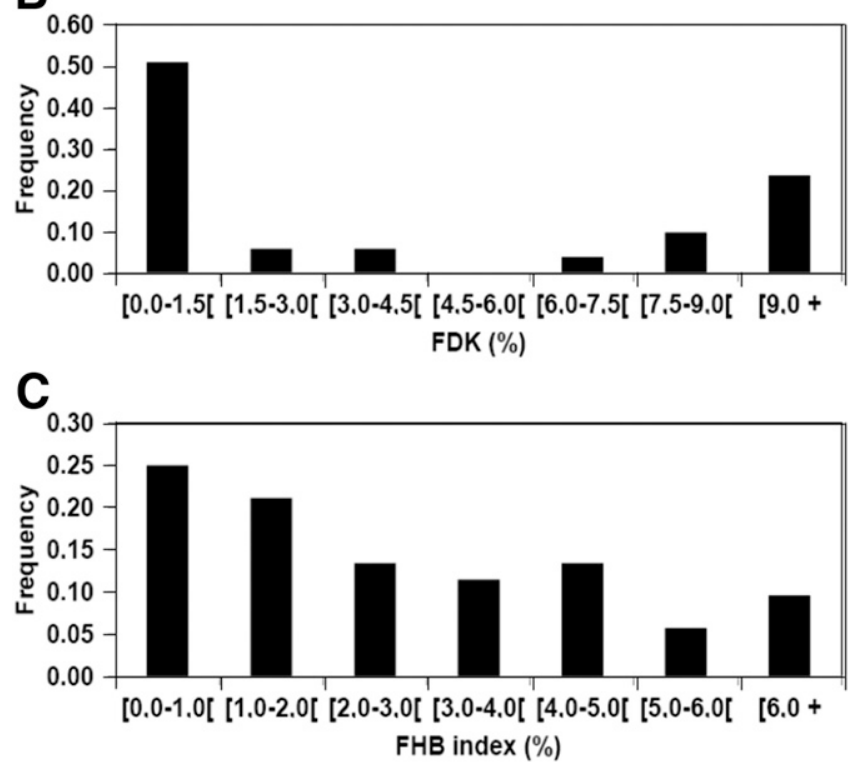

Fig. 1. Distribution of samples in the data set of $A$, deoxynivalenol (DON) content; B, Fusarium-damaged kernels (FDK); and C, Fusarium head blight (FHB) index. 
Statistics related to ROC curve analysis made with the observed phenological stages are presented in Table 4. AUC were generally different from 0.5 (no-information line). However, regardless of the crop damage indicator, the De Wolf I model was never different from $0.5(P>0.05)$, indicating that it had a low discriminatory power

Table 3. Prevalence of epidemic (cases) and nonepidemic (controls) situations in 2011 and 2012 samples for different Fusarium head blight (FHB) indicators

\begin{tabular}{|c|c|c|c|}
\hline $\begin{array}{l}\text { Crop damage } \\
\text { indicator }^{x}\end{array}$ & $\begin{array}{c}\text { Crop damage } \\
\text { threshold }\end{array}$ & $\begin{array}{c}\text { Prevalence of } \\
\text { cases }(\%)^{\mathrm{y}}\end{array}$ & $\begin{array}{l}\text { Prevalence of } \\
\text { controls }(\%)^{\mathrm{z}}\end{array}$ \\
\hline FHB index & $5 \%$ & 17.31 & 82.69 \\
\hline FHB index & $10 \%$ & 1.92 & 98.08 \\
\hline FDK & $1.0 \%$ & 61.54 & 38.46 \\
\hline FDK & $1.5 \%$ & 53.85 & 46.15 \\
\hline DON & $1 \mathrm{ppm}$ & 28.85 & 71.15 \\
\hline DON & $2 \mathrm{ppm}$ & 13.46 & 86.54 \\
\hline
\end{tabular}

${ }^{x}$ FHB index $=$ percentage of diseased spikelets (total number of infected spikelets/total number of spikelets $\times 100$ ), FDK = percentage of Fusariumdamaged kernels, and DON = deoxynivalenol content of wheat grain.

y Case $=$ sample $\geq$ threshold $=$ epidemic situation.

${ }^{\mathrm{z}}$ Control $=$ sample $<$ threshold $=$ nonepidemic situation . for cases and controls. This model was not better than chance to correctly predict FHB risk. AUC different from the no-information line of ROC curve analyses made with FDK $\geq 1 \%$ and FDK $\geq 1.5 \%$ varied from 0.694 to 0.822 and 0.636 to 0.778 , respectively (Table 4). For these two crop damage indicators, there was no significant difference between the AUC, which means that no model particularly stood out. For the analysis with DON $\geq 1 \mathrm{ppm}$, the AUC were generally higher than for FDK, ranging from 0.697 to 0.949 (except for De Wolf I). In addition, significant differences were observed between the AUC of several forecasting models. De Wolf A and De Wolf B had the highest AUC, which were 0.949 and 0.935 , respectively. Their Youden's index was not far from 1 (0.89 and 0.86), which showed that they were effective in predicting both cases and controls. The Moschini model was also effective, with an AUC of 0.914 and a Youden's index of 0.84 (Table 4). Other models had more or less equivalent performances, with AUC $<0.820$ and a Youden's index $\leq 0.60$. The crop damage indicator DON $\geq 1 \mathrm{ppm}$ seemed to be the one that best differentiated forecasting models when predictions were made with observed phenological stages. More precisely, De Wolf A and De Wolf B were superior to the others with accuracies of 0.92 and 0.90 , respectively (Table 5), which is the proportion of cases and controls correctly predicted. Furthermore, De Wolf A and De Wolf B had a sensitivity of $100 \%$ and a specificity

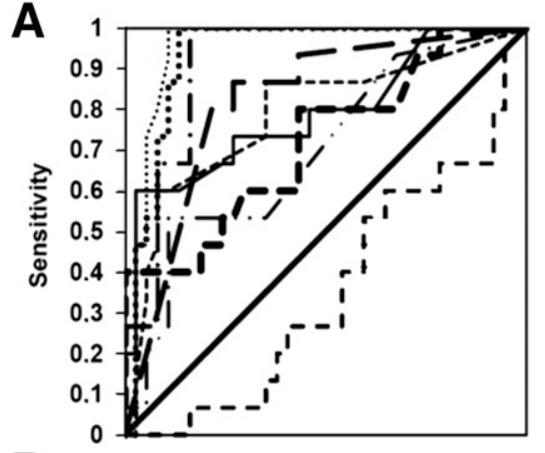

\section{B}

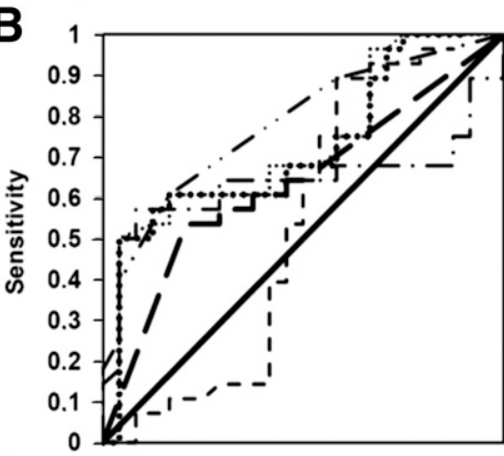

C

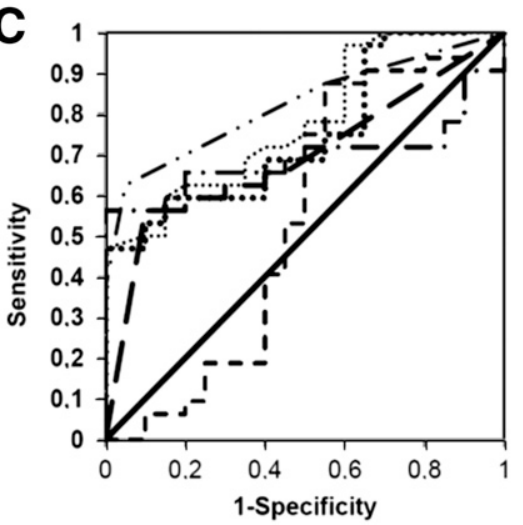

D

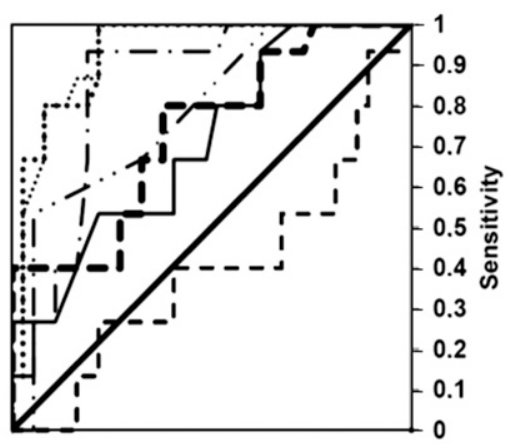

E

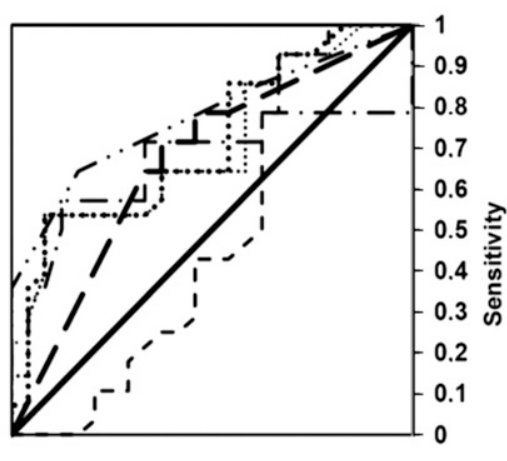

$F$

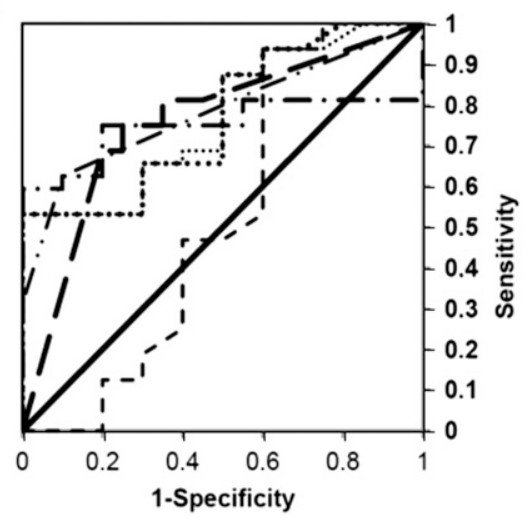

Hooker (- $)$

DONcast $(---\cdot-\cdot)$

De Wolf I $(--\cdot-\cdot)$

De Wolf B $(\cdots \cdots \cdots . . . .$.

De Wolf $A(\ldots \ldots . . . . . . . . . .$.

Molineros (-- - )

Moschini $(-\cdot-\cdot-\cdot)$

Rossi inf $(-\cdots-\cdots-)$

Rossi tox ( - - $)$

The no-information line is ( $\longrightarrow$ )

Fig. 2. Receiver operating characteristic (ROC) curves obtained for A, B, and C, observed phenological stages and D, E, and F, predicted phenological stages using damage indicators deoxynivalenol $\geq 1 \mathrm{ppm}(\mathrm{A}$ and $\mathrm{D})$, Fusarium-damaged kernels ( $\mathrm{FDK}) \geq 1.5 \%(\mathrm{~B}$ and $\mathrm{E})$, and $\mathrm{FDK} \geq 1 \%$ (C and $\mathrm{F}$ ). Nine forecasting models were included in the analyses. 
higher than $85 \%$, indicating that they correctly classified all cases in the data set and more than $85 \%$ of the controls using the optimal decision thresholds calculated from the Youden's index. The accuracy of the other models varied from 0.48 to 0.88 at their optimal decision thresholds. Three of the nine models had a sensitivity of $100 \%$ (De Wolf A, De Wolf B, and Moschini) while the others ranged from 6.7 to $86.7 \%$. Only one model had a specificity of $100 \%$ (Rossi tox), although the other models had correctly predicted between 64.9 and $97.3 \%$ of the controls (Table 5).

The results of ROC curve analysis using the predicted phenological stages are shown in Table 6. It should be noted that these are essentially the same parameters (crop damage indicators and models) as presented in Table 4, except that there are no results for DONcast. For the crop damage indicators FDK $\geq 1 \%$ and FDK $\geq 1.5 \%$, AUC were different from the no-information line for all models, except for De Wolf I, meaning that almost all models were better than chance for differentiating cases and controls. However, there were no significant differences between the AUC, which ranged from 0.521 to 0.783 and from 0.480 and 0.775 for the ROC curve analyses made with crop damage indicators FDK $\geq 1 \%$ and FDK $\geq 1.5 \%$, respectively (Table 6). For the crop damage indicator DON $\geq 1 \mathrm{ppm}$, AUC from all forecasting models were different from 0.5, except for De Wolf I. AUC ranged from 0.397 to 0.936 and were slightly lower than those obtained for this crop damage indicator with observed phenological stages. There were significant differences between the models, and these differences were similar to those obtained with the observed phenological stages data set. De Wolf A and De Wolf B stood out, while the other models had similar performances (Table 6). The accuracy of De Wolf A and De Wolf B was 0.85 , the sensitivity was $100.0 \%$, and the specificity was $78.4 \%$ at the optimal model

Table 4. Area under the receiver operating characteristic curve (AUC) and comparison with the line of no-information for each forecasting model using observed phenological stages with deoxynivalenol (DON) and Fusariumdamaged kernels (FDK) as damage indicators

\begin{tabular}{|c|c|c|c|c|c|}
\hline $\begin{array}{l}\text { Crop damage } \\
\text { indicator, } \\
\text { model }\end{array}$ & $\begin{array}{l}\text { Youden's } \\
\text { index }\end{array}$ & AUC & SE (Diff.) $)^{y}$ & Z-statistic & Significance $^{\mathrm{z}}$ \\
\hline \multicolumn{6}{|l|}{$\overline{\mathrm{DON}} \geq 1 \mathrm{ppm}$} \\
\hline De Wolf A & 0.89 & 0.949 & $0.032 \mathrm{a}$ & 5.03 & 0.000 \\
\hline De Wolf B & 0.86 & 0.935 & $0.035 \mathrm{ab}$ & 4.88 & 0.000 \\
\hline De Wolf I & -0.28 & 0.355 & $0.082 \mathrm{f}$ & 1.63 & 0.052 \\
\hline DONcast & 0.52 & 0.787 & $0.076 \mathrm{~cd}$ & 3.22 & 0.001 \\
\hline Hooker & 0.57 & 0.790 & $0.076 \mathrm{bd}$ & 3.25 & 0.001 \\
\hline Molineros & 0.60 & 0.819 & $0.063 \mathrm{de}$ & 3.58 & 0.000 \\
\hline Moschini & 0.84 & 0.914 & $0.039 \mathrm{abc}$ & 4.64 & 0.000 \\
\hline Rossi inf & 0.43 & 0.697 & $0.081 \mathrm{de}$ & 2.21 & 0.014 \\
\hline Rossi tox & 0.40 & 0.720 & $0.081 \mathrm{de}$ & 2.46 & 0.007 \\
\hline \multicolumn{6}{|l|}{$\mathrm{FDK} \geq 1 \%$} \\
\hline De Wolf I & 0.32 & 0.535 & $0.093 \mathrm{a}$ & 0.43 & 0.333 \\
\hline De Wolf B & 0.47 & 0.748 & $0.067 \mathrm{a}$ & 2.99 & 0.001 \\
\hline De Wolf A & 0.47 & 0.781 & $0.063 \mathrm{a}$ & 3.39 & 0.000 \\
\hline Molineros & 0.46 & 0.695 & $0.073 \mathrm{a}$ & 2.34 & 0.010 \\
\hline Moschini & 0.56 & 0.694 & $0.075 \mathrm{a}$ & 2.33 & 0.010 \\
\hline Rossi inf & 0.57 & 0.822 & $0.057 \mathrm{a}$ & 3.87 & 0.000 \\
\hline \multicolumn{6}{|l|}{$\mathrm{FDK} \geq 1.5 \%$} \\
\hline De Wolf I & 0.31 & 0.529 & $0.088 \mathrm{a}$ & 0.36 & 0.360 \\
\hline De Wolf B & 0.46 & 0.717 & $0.072 \mathrm{a}$ & 2.68 & 0.004 \\
\hline De Wolf A & 0.46 & 0.725 & $0.071 \mathrm{a}$ & 2.77 & 0.003 \\
\hline Molineros & 0.33 & 0.636 & $0.078 \mathrm{a}$ & 1.68 & 0.047 \\
\hline Moschini & 0.49 & 0.638 & $0.083 \mathrm{a}$ & 1.70 & 0.045 \\
\hline Rossi inf & 0.44 & 0.778 & $0.064 \mathrm{a}$ & 3.43 & 0.000 \\
\hline
\end{tabular}

y Standard error (SE) of the AUC. Letters following numbers indicate differences between AUC of the forecasting models based on pairwise comparisons according to DeLong et al. (1988). The same letters within the same damage indicator are not significantly different at $P \leq 0.05$.

${ }^{\mathrm{z}}$ Statistical significance of difference from 0.5 ( $P$ value); Z-statistic for the null hypothesis $\mathrm{H}_{0}$ : AUC $=0.5$ or line of no-information based on the Mann-Whitney $U$-statistic. decision threshold (Table 7). If we compare these performance parameters with those obtained with the observed phenological stages data set, cases were as correctly predicted and controls were less correctly classified in the data set. Other models had accuracies of 0.29 to 0.85 , which were generally lower than those produced with the observed phenological stages (except Rossi inf). Sensitivity values were 53.3 to $93.3 \%$. No model correctly predicted all controls, with specificities ranging from 18.9 to $94.6 \%$ (Table 7). If we compare these values with those of Table 5, we cannot see any general trend: some parameters increased or decreased depending on the model for

Table 5. Performance parameters for adjusted threshold of forecasting models using observed phenological stages with deoxynivalenol $\geq 1 \mathrm{ppm}$ as damage indicator

\begin{tabular}{lcccc}
\hline Model & $\begin{array}{c}\text { Optimal } \\
\text { decision } \\
\text { threshold }^{\mathbf{w}}\end{array}$ & Accuracy $^{\mathbf{x}}$ & Sensitivity $(\%)$ & ${\text { Specificity }(\%)^{\mathbf{z}}}^{\mathbf{y}}$ \\
\hline De Wolf A & 0.32 & 0.92 & 100.0 & 89.2 \\
De Wolf B & 0.31 & 0.90 & 100.0 & 86.5 \\
De Wolf I & 0.83 & 0.48 & 6.7 & 64.9 \\
DONcast & 1.00 & 0.83 & 60.0 & 91.9 \\
Hooker & 3.4 & 0.87 & 60.0 & 97.3 \\
Molineros & 48.5 & 0.77 & 86.7 & 73.0 \\
Moschini & 45.0 & 0.88 & 100.0 & 83.8 \\
Rossi inf & 0.3 & 0.79 & 53.3 & 89.2 \\
Rossi tox & 15.6 & 0.83 & 40.0 & 100.0 \\
\hline
\end{tabular}

w Optimal decision threshold based on Youden's index as $\mathrm{J}=$ sensitivity + specificity -1 .

x Prevalence of cases and controls correctly classified.

y Prevalence of cases correctly classified.

${ }^{\mathrm{z}}$ Prevalence of controls correctly classified.

Table 6. Area under the receiver operating characteristic curve (AUC) and comparison with the line of no-information for each forecasting model using predicted phenological stages with deoxynivalenol (DON) and Fusariumdamaged kernels (FDK) as damage indicators

\begin{tabular}{lccccc}
\hline $\begin{array}{l}\text { Crop damage } \\
\text { indicator, } \\
\text { model }\end{array}$ & $\begin{array}{c}\text { Youden's } \\
\text { index }\end{array}$ & AUC & SE (Diff.) $)$ & Z-statistic & Significance $^{\mathbf{z}}$ \\
\hline DON $\geq 1 \mathrm{ppm}$ & & & & & \\
De Wolf A & 0.78 & 0.936 & $0.032 \mathrm{a}$ & 4.89 & 0.000 \\
De Wolf B & 0.78 & 0.932 & $0.034 \mathrm{a}$ & 4.85 & 0.000 \\
De Wolf I & -0.28 & 0.397 & $0.090 \mathrm{~d}$ & 1.15 & 0.125 \\
Hooker & 0.32 & 0.702 & $0.077 \mathrm{~b}$ & 2.26 & 0.012 \\
Molineros & 0.61 & 0.796 & $0.066 \mathrm{bc}$ & 3.32 & 0.000 \\
Moschini & 0.74 & 0.853 & $0.054 \mathrm{ab}$ & 3.96 & 0.000 \\
Rossi inf & 0.48 & 0.784 & $0.068 \mathrm{bc}$ & 3.18 & 0.001 \\
Rossi tox & 0.42 & 0.738 & $0.076 \mathrm{bc}$ & 2.67 & 0.004 \\
FDK $\geq 1 \%$ & & & & & \\
De Wolf I & 0.34 & 0.521 & $0.095 \mathrm{a}$ & 0.26 & 0.396 \\
De Wolf B & 0.53 & 0.769 & $0.065 \mathrm{a}$ & 3.24 & 0.001 \\
De Wolf A & 0.53 & 0.769 & $0.065 \mathrm{a}$ & 3.24 & 0.001 \\
Molineros & 0.50 & 0.758 & $0.070 \mathrm{a}$ & 3.10 & 0.001 \\
Moschini & 0.59 & 0.750 & $0.071 \mathrm{a}$ & 3.01 & 0.001 \\
Rossi inf & 0.52 & 0.783 & $0.063 \mathrm{a}$ & 3.40 & 0.000 \\
FDK $\geq 1.5 \%$ & & & & & \\
De Wolf I & 0.26 & 0.480 & $0.087 \mathrm{a}$ & 0.24 & 0.406 \\
De Wolf B & 0.45 & 0.714 & $0.072 \mathrm{a}$ & 2.64 & 0.004 \\
De Wolf A & 0.45 & 0.704 & $0.073 \mathrm{a}$ & 2.52 & 0.006 \\
Molineros & 0.34 & 0.668 & $0.077 \mathrm{a}$ & 2.07 & 0.019 \\
Moschini & 0.45 & 0.664 & $0.079 \mathrm{a}$ & 2.02 & 0.022 \\
Rossi inf & 0.48 & 0.775 & $0.065 \mathrm{a}$ & 3.40 & 0.000 \\
\hline
\end{tabular}

y Standard error (SE) of the AUC. Letters following numbers indicate differences between AUC of the forecasting models based on pairwise comparisons according to DeLong et al. (1988). The same letters within the same damage indicator are not significantly different at $P \leq 0.05$.

${ }^{\mathrm{z}}$ Statistical significance of difference from 0.5 ( $P$ value); Z-statistic for the null hypothesis $\mathrm{H}_{0}$ : AUC $=0.5$ or line of no-information based on the Mann-Whitney $U$-statistic. 
the predicted versus observed phenological stages data sets. The crop damage indicator DON $\geq 1 \mathrm{ppm}$ seemed, again, to be the one with the highest discriminating power. In general, the AUC and accuracies obtained with predicted phenological stages for most FHB forecasting models were lower than those obtained with observed phenological stages (Tables 4 to 7). Based on these lower performances using predicted phenological stages, predictions based on DONcast were not requested from Weather INnovations Consulting LP for this part of the ROC curve analysis.

Selection of optimal model decision threshold. The highest Youden's index for each forecasting model is presented in Table 4 for ROC curve analyses with the observed phenological stages and in Table 6 for those made with predicted phenological stages. In both types of analysis, the Youden's index was generally lower for crop damage indicators FDK $\geq 1 \%$ and FDK $\geq 1.5 \%$. If Youden's index for the observed phenological stages is compared with those of predicted phenological stages, some differences can be noted. For damage indicators FDK $\geq 1 \%$ and FDK $\geq 1.5 \%$, they were of approximately the same order of magnitude. Youden's index for the observed phenological stages was 0.31 to 0.57 and 0.26 to 0.59 for the predicted phenological stages (Tables 4 and 6). For DON $\geq 1 \mathrm{ppm}$, there was a decrease in Youden's index with the predicted phenological stages for De Wolf B, De Wolf A, Hooker, and Moschini. Other models had a Youden's index slightly higher. Therefore, lower Youden's index reflected a decrease in precision of the ROC curve analysis with predicted stages.

The optimal model decision threshold is calculated from the Youden's index and minimizes errors with the data set used. Because the crop damage indicator $\mathrm{DON} \geq 1 \mathrm{ppm}$ was the most discriminating, $\mathrm{LR}+$ and LR- derived from this analysis were used for selecting the optimal decision threshold for each model. The decision threshold was adjusted when compared with the published decision threshold, except for Moschini, Rossi inf, and Rossi tox, because they did not provide such thresholds for their models. For observed and predicted phenological stages, the optimal model decision thresholds were lower than the published decision thresholds for De Wolf $\mathrm{A}$ and De Wolf B, whereas other models had optimal decision threshold higher than or equivalent to the published ones (Tables 8 and 9). De Wolf I will not be discussed, because it was not different from the no-information line, although its results appear in Tables 8 and 9. For results of De Wolf B with observed phenology, LR+ was unchanged and LR- was lower, which means that the optimal model decision threshold increased the specificity of the model (Table 8). For De Wolf A, LR+ were higher than for the other models and, thus, had the best decision threshold, while the LR- was also lower, which means that the optimal model decision threshold increased the accuracy of the model in the presence and in the absence of disease (Table 8). DONcast had an LR+ and LR- higher than the optimal decision threshold. Thus, the model was better under epidemic

Table 7. Performance parameters for the adjusted threshold of forecasting models using predicted phenological stages with deoxynivalenol $\geq 1 \mathrm{ppm}$ as damage indicator

\begin{tabular}{|c|c|c|c|c|}
\hline Model & $\begin{array}{l}\text { Optimal } \\
\text { decision } \\
\text { threshold }\end{array}$ & Accuracy $^{x}$ & Sensitivity $(\%)^{\mathrm{y}}$ & Specificity $(\%)^{\mathrm{z}}$ \\
\hline De Wolf A & 0.23 & 0.85 & 100.0 & 78.4 \\
\hline De Wolf B & 0.29 & 0.85 & 100.0 & 78.4 \\
\hline De Wolf I & 0.50 & 0.29 & 53.3 & 18.9 \\
\hline Hooker & 2.3 & 0.71 & 53.3 & 78.4 \\
\hline Molineros & 90.3 & 0.75 & 93.3 & 67.6 \\
\hline Moschini & 45.0 & 0.85 & 93.3 & 81.1 \\
\hline Rossi inf & 0.3 & 0.83 & 53.3 & 94.6 \\
\hline Rossi tox & 6.1 & 0.67 & 80.0 & 62.2 \\
\hline
\end{tabular}

situations but was somewhat less effective in nonepidemic situations. The optimal model decision threshold of Hooker produced an LR+ and LR- lower than the published threshold, which means that the model became less effective in the presence of disease but more accurate in its absence. Finally, the optimal decision threshold for Molineros was equivalent to the published one (Table 8). With the predicted phenological stages, LR+ and LR- for the optimal decision threshold of De Wolf A and De Wolf B were lower than the published threshold, indicating that the adjusted threshold was less efficient at predicting the presence of disease but was more accurate at predicting its absence (Table 9). For the optimal decision thresholds of Hooker and Molineros, the LR+ was superior and the LR- was inferior compared with the published threshold. Thus, their optimal thresholds were better than their published ones in epidemic and nonepidemic situations under the climatic conditions of the province of Quebec.

\section{Discussion}

FHB is an appropriate disease for modeling in wheat crops given that it can vary substantially depending on weather conditions, while the period of wheat susceptibility is narrow and economic losses associated with grade reductions and mycotoxins are high (Prandini et al. 2009). Although several researchers have developed forecasting models for FHB in wheat around the world, no model has been implemented in Quebec. Currently, in the province, the pest management warning network (Réseau d'avertissements phytosanitaires

Table 8. Likelihood ratios of positive prediction ( $\mathrm{LR}+)$ and of negative prediction (LR-) for the adjusted and published decision threshold of each model using observed phenological stages, with deoxynivalenol $\geq 1 \mathrm{ppm}$ as damage indicator

\begin{tabular}{lcccccc}
\hline Model & $\begin{array}{c}\text { Optimal } \\
\text { decision } \\
\text { threshold }^{\mathbf{w}}\end{array}$ & $\mathbf{L R +}^{\mathbf{x}}$ & $\mathbf{L R - \mathbf { y }}$ & $\begin{array}{c}\text { Published }^{\text {threshold }} \mathbf{z}^{\mathbf{z}} \\
\text { LR+ }\end{array}$ & $\mathbf{L R -}$ \\
\hline De Wolf A & 0.32 & 9.25 & 0.00 & 0.36 & 8.63 & 0.07 \\
De Wolf B & 0.31 & 7.40 & 0.00 & 0.44 & 7.40 & 0.22 \\
De Wolf I & 0.83 & 0.19 & 1.44 & 0.50 & 0.93 & 1.14 \\
DONcast & 1.00 & 7.40 & 0.44 & 0.1 & 1.46 & 0.33 \\
Hooker & 3.4 & 2.22 & 0.41 & 2.0 & 2.74 & 0.44 \\
Molineros & 48.5 & 3.21 & 0.18 & 50.0 & 3.21 & 0.18 \\
Moschini & 45.0 & 6.17 & 0.00 & n.a. & $\ldots$ & $\ldots$ \\
Rossi inf & 0.25 & 4.93 & 0.52 & n.a. & $\ldots$ & $\ldots$ \\
Rossi tox & 15.6 & $(0.4 / 0)$ & 0.60 & n.a. & $\ldots$ & $\ldots$ \\
\hline
\end{tabular}

${ }^{\mathrm{w}}$ Adjusted threshold based on Youden's index as $\mathrm{J}=$ sensitivity + specificity -1 .

${ }^{x}$ LR of a positive prediction $(\mathrm{LR}+)=$ sensitivity $/(1-$ specificity $)$.

${ }^{y}$ LR of a negative prediction (LR-) $=(1-$ sensitivity $) /$ specificity.

${ }^{\mathrm{z}}$ Action threshold published in the literature; n.a.= not available (no action threshold published in the literature).

Table 9. Likelihood ratios of positive prediction $(\mathrm{LR}+)$ and of negative prediction (LR-) for the adjusted and published decision threshold of each model using predicted phenological stages, with deoxynivalenol $\geq 1 \mathrm{ppm}$ as damage indicator

\begin{tabular}{lcccccc}
\hline & $\begin{array}{c}\text { Optimal } \\
\text { decision } \\
\text { threshold }\end{array}$ & LR+x & LR-y & $\begin{array}{c}\text { Published } \\
\text { threshold }\end{array}$ & LR+ & LR- \\
\hline Predictor & 0.23 & 4.63 & 0.00 & 0.36 & 5.92 & 0.23 \\
De Wolf A & 0.29 & 4.63 & 0.00 & 0.44 & 5.92 & 0.23 \\
De Wolf B & 0.29 & 0.66 & 2.47 & 0.50 & 0.66 & 2.47 \\
De Wolf I & 0.50 & 2.4 & 0.60 & 2.0 & 1.52 & 0.72 \\
Hooker & 2.3 & 2.88 & 0.10 & 50.0 & 2.30 & 0.11 \\
Molineros & 90.3 & 4.93 & 0.08 & n.a. & $\ldots$ & $\ldots$ \\
Moschini & 45.0 & 9.87 & 0.49 & n.a. & $\ldots$ & $\ldots$ \\
Rossi inf & 0.3 & 2.11 & 0.32 & n.a. & $\ldots$ & $\ldots$ \\
Rossi tox & 6.1 & $\ldots$ &
\end{tabular}

w Optimal decision threshold based on Youden's index as J = sensitivity + specificity -1

${ }^{\mathrm{x}} \mathrm{LR}$ of a positive prediction $(\mathrm{LR}+)=$ sensitivity/( $1-$ specificity $)$.

${ }^{y}$ LR of a negative prediction (LR-) $=(1-$ sensitivity)/specificity.

${ }^{\mathrm{z}}$ Action threshold published in the literature; n.a. = not available (no action threshold published in the literature). 
2000-2014) produces regional estimated risks of disease based on observed and forecasted weather conditions but no mathematical algorithm is used. The evaluation of the effectiveness of forecasting models developed abroad is essential to create a tool for assessing the risk of FHB and guiding fungicide application under the climatic conditions of Quebec. Such a risk-assessment tool could be used by farmers and agricultural stakeholders in an integrated pest management approach. A forecasting model would allow for optimization of fungicide application, allow farmers to target a particular market before harvest, and guide millers for grain sampling frequency according to the predicted regional disease pressure (Landschoot et al. 2013).

Regarding the samples used in the current study, the frequency distributions reflect the weather conditions that occurred during the two experimental seasons (Fig. 1). Weather conditions were favorable to FHB at only two sites in 2011. Indeed, nonepidemic situations (i.e., controls) are mainly expressed by four of six crop damage indicators (Table 3). The crop damage indicators chosen to identify epidemic situations (i.e., cases) are too high for the frequency distribution of these indicators. They were selected independently of the distribution of FHB index and DON content and they are justified by Canadian regulations and by literature (Canadian Food Inspection Agency 2012; De Wolf et al. 2003). Thus, symptoms on heads at the milky stage (FHB index) and DON content $\geq 2$ ppm were not present in enough samples to be used as a crop damage indicator for ROC curve analyses (Janes and Pepe 2006). Only thresholds chosen for the FDK crop damage indicator have created data sets with a majority of epidemic situations. For this crop damage indicator, the thresholds were chosen according to the Canadian regulations (Canadian Grain Commission 2015) but were relatively low when looking at the entire frequency distribution, which could explain the high rate of epidemic situations. Nevertheless, both FDK crop damage indicators and DON $\geq 1 \mathrm{ppm}$ met the proportion 25 to $75 \%$ and can be used for ROC curve analyses (Janes and Pepe 2006). In addition, DON $\geq 1$ ppm was the most effective crop damage indicator to differentiate epidemic situations from nonepidemic situations. The AUC were generally higher than those obtained with the crop damage indicators of FDK and it was the only indicator that provided significant differences among FHB forecasting models when they were compared (Tables 4 and 6). It is also a relevant crop damage threshold to apply in Quebec because the accepted limit of DON in wheat for human consumption is 2 ppm (Canadian Food Inspection Agency 2012). An effective model that predicted whether DON content was more or less likely to exceed $1 \mathrm{ppm}$ would give relevant information to be used by farmers to avoid costly and unnecessary fungicide applications at flowering. The FDK crop damage indicators seemed less effective to differentiate epidemic situations from nonepidemic situations in the context of modeling because the AUC were lower and there were no significant differences among the models (Tables 4 and 6). A suboptimal ratio of epidemic situations and nonepidemic situations (Janes and Pepe 2006) or the variability caused by the visual assessment of the disease could explain the lower performance of FHB forecasting models with FDK as crop damage indicators (Madden et al. 2007; Rossi et al. 2010).

Field observation of wheat phenology was essential for good modeling results. Even if the crop damage indicator DON $\geq 1 \mathrm{ppm}$ stood out in the two types of ROC curve analysis, model performances were better when phenology was observed and not predicted by the model developed at Agriculture and Agri-Food Canada. Indeed, the phenology model did not predict with sufficient accuracy the dates of the critical stages for infection (Z51, Z58, and Z65), which had a great influence on the response of the forecasting model of FHB. The weather conditions of the days surrounding flowering are critical for the potential risk of infection, especially because the De Wolf B and De Wolf A models have anthesis (Z65) as a critical reference point (Bailey et al. 2004; De Wolf et al. 2003; Moschini et al. 2001). De Wolf B uses weather data before and after anthesis, while De Wolf A only uses conditions after anthesis. Therefore, if this critical stage is not correctly identified, it could lead to a decrease in model effectiveness, especially for those models that are the most accurate. The use of bioclimatic models to predict the date of specific phenological stages from seeding date, in their current state, should be considered only for helping farmers and consultants with planning field visits to confirm that the crop is getting close to the critical growth stages for FHB disease forecasting.

The performances of selected forecasting models can be divided in two groups. First, the two American models (De Wolf A and De Wolf B) and the Argentinean model (Moschini) had good combinations of accuracy, sensitivity, and specificity with their optimal decision threshold after the ROC curve analysis was performed using DON $\geq 1$ ppm as the crop damage indicator and observed phenology. It is interesting to note that these forecasting models resulted in better predictions than other selected forecasting models, even if they were not developed to predict DON levels but mainly field FHB disease incidence or severity. Furthermore, as shown by Paul et al. (2005), there is a lot of variation in the relationship between DON levels and FDK severity at the field level. Therefore, a forecasting model developed to predict FDK severity would not necessarily be appropriate for predicting DON levels, which is not the case for the data collected in this study. It seems that these three models captured adequately the climate conditions conducive to infection and DON development in the grain. In comparison with these models, another American model (Molineros) underperformed, especially in terms of specificity (73\%) (Table 5). This model uses only weather data of the 7 days before anthesis and does not take into consideration favorable conditions occurring during the postflowering period, which could explain its low accuracy (De Wolf et al. 2003). Those results indicate that fungicide treatments would be recommended when conditions are not favorable to FHB development when using Molineros model.

Those four forecasting models (De Wolf A, De Wolf B, Moschini, and Molineros) are empirical models that predict the infection risks with simple polynomial equations. The principle of parsimony should be used in modeling, which means that simplicity is preferable to complexity (Prandini et al. 2009; Rossi et al. 2010). More specifically, models must have the best efficiency using the fewest possible variables without a reduction in performance. Although complexity can make a model more accurate, it can also make it less usable (Rossi et al. 2010). After ROC curve analyses, we found that it was the simplest models that performed the best, which is in agreement with the principle of parsimony. In addition, the simplest models will be easier to implement into a provincial weather forecasting system of FHB risk. The other group included models from Canada (DONcast and Hooker) and Italy (Rossi inf and Rossi tox). They underperformed with sensitivity of $60,60,53$, and $40 \%$, respectively (Table 5). Using those models, fungicide treatments would not be recommended when weather conditions are favorable to FHB. This situation is not desirable in a program to reduce the impact of FHB. Finally, the De Wolf I model from the United States never gave reliable predictions with accuracy less than 50\% (Table 5). The sensitivity $(6.7 \%)$ and specificity $(64.9 \%)$ were particularly low, which means that few epidemic and nonepidemic situations were correctly classified. Thus, with the De Wolf I model, fungicide applications would be omitted in the presence of FHB, while many applications would be recommended in the absence of the disease. The data used in this study were limited to two growing seasons and did not reflect all possible weather conditions that could favor the development of FHB. Further evaluation is required to confirm the accuracy of the selected forecasting models, particularly for those that appear to be superior, and the potential of recently developed forecasting models.

Another objective of this study was to determine the optimal model decision threshold suited to climatic conditions occurring in Quebec. The optimal model decision thresholds calculated from the Youden's index of the ROC curve analysis done with the crop damage indicator DON $\geq 1 \mathrm{ppm}$ and observed phenology were more adapted to the climate of Quebec than the published thresholds. They should be used with the selected models for the province. In using those optimal decision thresholds, we considered equal costs of FPP and false negatives. However, for FHB of wheat, an unnecessary application of fungicide for a false positive costs less than crop losses 
due to an epidemic situation (Bondalapati et al. 2012). Thresholds of De Wolf A, De Wolf B, and Moschini could have been adjusted to the relative cost of errors in their study to have better decision thresholds adapted economically (Bondalapati et al. 2012; McRoberts et al. 2011).

The development of a highly effective forecasting model of FHB does not guarantee its success among farmers. Although the model has been proven functional, farmers often perceive it in a negative way and see higher risks to use this unknown system in comparison with their usual method of decision (Gent et al. 2011; McCown 2002; McRoberts et al. 2011). The need, credibility, and effectiveness of a forecasting model must be established within the farmer community before the majority considers adoption (McCown 2002). In addition, the data required for the proper functioning of the forecasting model can be a limiting factor for its adoption. For example, the quantity of information requested on field history can be an obstacle to model adoption (Schaafsma and Hooker 2007). Despite many limitations, the implementation of a forecasting model for wheat FHB is an interesting tool to reduce pesticides in agriculture and to promote principles of integrated pest management. In the end, after little adjustments, simple models have proven their efficacy under growing conditions of Quebec. Their implementation will be the next challenge.

\section{Acknowledgments}

This work was supported by the Pesticide Risk Reduction Program of Agriculture and Agri-Food Canada (AAFC) and by the Natural Sciences and Engineering Research Council of Canada. This collaborative project would not have been possible without the work of many people who have provided guidance and technical support throughout the years. We thank I. Morasse, D. Choquette, D. Plouffe, and N. Beaudry from AAFC; V. Bélanger, M.-E. Bernard, and A. Brégard from Laval University; C. Danjou and N. Bourget from CÉROM; and all of the technical assistants and summer students of the Agronomy Research Station of Laval University at Saint-Augustin-de-Desmaures, the Horticulture R\&D Centre of AAFC at Saint-Jean-sur-Richelieu, the CÉROM at Saint-Mathieu-de-Beloeil and Québec, and AAFC at Normandin.

\section{Literature Cited}

Allaire, J. F., and Cismaru, D. 2007. ROCTools_-A statistical software for the analysis of ROC curves. Statistics Consulting Group of Centre de recherche de l'Institut Philippe-Pinel de Montréal, Montréal.

Bailey, K. L., Couture, L., Gossen, B. D., Gugel, R. K., and Morral, R. A. A. 2004. Maladie des grandes cultures au Canada, 1st ed. La Société Canadienne de Phytopathologie, Saskatoon, SK, Canada.

Biggerstaff, B. J. 2000. Comparing diagnostic tests: A simple graphic using likelihood ratios. Stat. Med. 19:649-663.

Bondalapati, K. D., Stein, J. M., Neate, S. M., Halley, S. H., Osborne, L. E., and Hollingsworth, C. R. 2012. Development of weather-based predictive models for Fusarium head blight and deoxynivalenol accumulation for spring malting barley. Plant Dis. 96:673-680.

Canadian Food Inspection Agency. 2012. RG-8 regulatory guidance: Contaminants in feed. Section 1: Mycotoxins in livestock feed. Online publication. http://www.inspection.gc.ca/animals/feeds/regulatory-guidance/rg-8/eng/ $1347383943203 / 1347384015909$ ?chap $=1$

Canadian Grain Commission. 2015. Official Grain Grading Guide. Online publication. https://www.grainscanada.gc.ca/oggg-gocg/oggg-gocg-2015eng.pdf

Carisse, O., McRoberts, N., and Brodeur, L. 2008. Comparison of monitoring- and weather-based risk indicators of Botrytis leaf blight of onion and determination of action thresholds. Can. J. Plant Pathol. 30:442-456.

DeLong, E. R., DeLong, D. M., and Clarke-Pearson, D. L. 1988. Comparing the areas under two or more correlated receiver operating characteristic curves: A nonparametric approach. Biometrics 44:837-845.

Del Ponte, E. M., Fernandes, J. M. C., and Pavan, W. 2005. A risk infection simulation model for Fusarium head blight of wheat. Fitopatol. Bras. 30: 634-642.

Desjardins, A. E. 2006. Fusarium Mycotoxins: Chemistry, Genetics and Biology. American Phytopathological Society, St. Paul, MN.

Dewdney, M. M., Biggs, A. R., and Turechek, W. W. 2007. A statistical comparison of the blossom blight forecasts of MARYBLYT and Cougarblight with receiver operating characteristic curve analysis. Phytopathology 97:1164-1176.

De Wolf, E. D., and Isard, S. A. 2007. Disease cycle approach to plant disease prediction. Annu. Rev. Phytopathol. 45:203-220.

De Wolf, E. D., Madden, L. V., and Lipps, P. E. 2003. Risk assessment models for wheat Fusarium head blight epidemics based on within-season weather data. Phytopathology 93:428-435.

Duttweiler, K. B., Gleason, M. L., Dixon, P. M., Sutton, T. B., McManus, P. S., and Monteiro, J. E. B. A. 2008. Adaptation of an apple sooty blotch and flyspeck warning system for the upper Midwest United States. Plant Dis. 92 $1215-1222$

Elegbede, C. F., Pierrat, J.-C., Aguayo, J., Husson, C., Halkett, F., and Marçais, B 2010. A statistical model to detect asymptomatic infectious individuals with an application in the Phytophthora alni induced alder decline. Phytopathology 100:1262-1269.

Gent, D. H., De Wolf, E. D., and Pethybridge, S. J. 2011. Perceptions of risk, risk aversion, and barriers to adoption of decision support systems and integrated pest management: An introduction. Phytopathology 101:640-643.

Hanley, J. A., and McNeil, B. J. 1982. The meaning and use of the area under a receiver operating characteristic (ROC) curve. Radiology 143:29-36.

Hanley, J. A., and McNeil, B. J. 1983. A method of comparing the areas under receiver operating characteristic curves derived from the same cases. Radiology 148:839-843.

Haran, M., Bhat, K. S., Molineros, J., and De Wolf, E. D. 2010. Estimating the risk of a crop epidemic from coincident spatio-temporal processes. J. Agric. Biol. Environ. Stat. 15:158-175.

Hooker, D. C., Schaafsma, A. W., and Tamburic-Ilincic, L. 2002. Using weather variables pre- and post-heading to predict deoxynivalenol content in winter wheat. Plant Dis. 86:611-619.

Hughes, G., McRoberts, N., and Burnett, F. J. 1999. Decision-making and diagnosis in disease management. Plant Pathol. 48:147-153.

Janes, H., and Pepe, M. 2006. The optimal ratio of cases to controls for estimating the classification accuracy of a biomarker. Biostatistics 7:456-468.

Landschoot, S., Waegeman, W., Audenaert, K., Van Damme, P., Vandepitte, J., De Baets, B., and Haesaert, G. 2013. A field-specific web tool for the prediction of Fusarium head blight and deoxynivalenol content in Belgium. Comput. Electron. Agric. 93:140-148.

Madden, L. V. 2006. Botanical epidemiology: Some key advances and its continuing role in disease management. Eur. J. Plant Pathol. 115:3-23.

Madden, L. V., Hughes, G., and van den Bosh, F. 2007. The Study of Plant Disease Epidemics. American Phytopathological Society, St. Paul, MN.

McCown, R. L. 2002. Changing systems for supporting farmers' decisions: Problems, paradigms, and prospects. Agric. Syst. 74:179-220.

McMullen, M., Bergstrom, G., De Wolf, E., Dill-Macky, R., Hershman, D., Shaner, G., and Van Sanford, D. 2012. A unified effort to fight an enemy of wheat and barley: Fusarium head blight. Plant Dis. 96:1712-1728.

McMullen, M., Jones, R., and Gallenberg, D. 1997. Scab of wheat and barley: A reemerging disease of devastating impact. Plant Dis. 81:1340-1348.

McRoberts, N., Hall, C., Madden, L. V., and Hughes, G. 2011. Perceptions of disease risk: From social construction of subjective judgments to rational decision making. Phytopathology 101:654-665.

Metz, C. E. 1978. Basic principles of ROC analysis. Semin. Nucl. Med. 8:283-298.

Molineros, J. 2007. Understanding the challenge of Fusarium head blight forecasting. Ph.D. thesis, The Pennsylvania State University, University Park.

Moschini, R. C., Carranza, M. R., and Carmona, M. A. 2004. Meteorologicalbased predictions of wheat head blight epidemic in the southern Argentinean Pampas region. Cereal Res. Commun. 32:45-52.

Moschini, R. C., and Fortugno, C. 1996. Predicting wheat head blight incidence using models based on meteorological factors in Pergamino, Argentina. Eur. J. Plant Pathol. 102:211-218.

Moschini, R. C., Pioli, R., Carmona, M. A., and Sacchi, O. 2001. Empirical predictions of wheat head blight in the northern Argentinean Pampas region Crop Sci. 41:1541-1545.

Musa, T., Hecker, A., Vogelgsang, S., and Forrer, H. R. 2007. Forecasting of Fusarium head blight and deoxynivalenol content in winter wheat with FusaProg. EPPO Bull. 37:283-289.

Parry, D. W., Jenkinson, P., and McLeod, L. 1995. Fusarium ear blight (scab) in small grain cereals - a review. Plant Pathol. 44:207-238.

Paul, P. A., Lipps, P. E., and Madden, L. V. 2005. Relationship between visual estimates of Fusarium head blight intensity and deoxynivalenol accumulation in harvested wheat grain: A meta-analysis. Phytopathology 95:1225-1236.

Peel, M. C., Finlayson, B. L., and McMahon, T. A. 2007. Updated world map of the Köppen-Geiger climate classification. Hydrol. Earth Syst. Sci. 4 439-473.

Plouffe, D., Bourgeois, G., Beaudry, N., Chouinard, G., and Choquette, D. 2014 CIPRA-Computer Centre for Agricultural Pest Forecasting: Crop Guide. Tech. Bull. A42-119/2013E-PDF. Online publication. Agriculture and AgriFood Canada. http://www.publications.gc.ca/pub?id=9.698631\&sl=0

Prandini, A., Sigolo, S., Filippi, L., Battilani, P., and Piva, G. 2009. Review of predictive models for Fusarium head blight and related mycotoxin contamination in wheat. Food Chem. Toxicol. 47:927-931.

Réseau d'avertissements phytosanitaires. 2000-2014. Grandes Cultures, Maladies: Fusariose de l'épi et de l'orge. Online publications. https://www.agrireseau. net/rap/documents?s=2392\&page $=1$

Réseaux Grandes Cultures du Québec. 2011. Résultats 2011 et recommandations 2012 des RGCQ. Online publication. http://cerom.qc.ca/assets/contenu/docs/ guides/Resultats_RGCQ_2011.pdf

Rossi, V., Giosuè, S., and Caffi, T. 2010. Modelling plant diseases for decision making in crop protection. Pages 241-258 in: Precision Crop Protection-The Challenge and Use of Heterogeneity. E.-C. Oerke, R. Gerhards, G. Menz, and R. A. Sikora, eds. Springer Science, Dordrecht, The Netherlands. 
Rossi, V., Giosuè, S., Pattori, E., Spanna, F., and Del Vecchio, A. 2003. A model estimating the risk of Fusarium head blight on wheat. EPPO Bull. 33:421-425.

Schaafsma, A. W., and Hooker, D. C. 2007. Climatic models to predict occurrence of Fusarium toxins in wheat and maize. Int. J. Food Microbiol. 119:116-125.

Shah, D. A., De Wolf, E. D., Paul, P. A., and Madden, L. V. 2014. Predicting Fusarium head blight epidemics with boosted regression trees. Phytopathology 104:702-714.

Shah, D. A., Molineros, J. E., Paul, P. A., Willyerd, K. T., Madden, L. V., and De Wolf, E. D. 2013. Predicting Fusarium head blight epidemics with weatherdriven pre- and post-anthesis logistic regression models. Phytopathology 103: 906-919.

Turechek, W. W., and Wilcox, W. F. 2005. Evaluating predictors of apple scab with receiver operating characteristic curve analysis. Phytopathology 95:679-691.
Van Der Fels-Klerx, H. J., Burgers, S. L. G. E., and Booij, C. J. H. 2010 Descriptive modelling to predict deoxynivalenol in winter wheat in the Netherlands. Food Addit. Contam. 27:636-643.

Váňová, M., Klem, K., Matušinský, P., and Trnka, M. 2009. Prediction model for deoxynivalenol in wheat grain based on weather conditions. Plant Prot. Sci. 45 S33-S37.

Wu, B. M., van Bruggen, A. H. C., Subbarao, K. V., and Scherm, H. 2002. Incorporation of temperature and solar radiation thresholds to modify a lettuce downy mildew warning system. Phytopathology 92:631-636.

Yuen, J. E., and Hughes, G. 2002. Bayesian analysis of plant disease prediction. Plant Pathol. 51:407-412.

Zadoks, J. C., Chang, T. T., and Konzak, C. F. 1974. A decimal code for the growth stages of cereals. Weed Res. 14:415-421. 